\title{
The Effect of Intratympanic Injection of Dexamethasone for the Treatment of Sudden Sensorineural Hearing Loss
}

\author{
MOSTAFA R.A. LOTFY, M.Sc.*; AMANI M.N. EL-GHARIB, M.D.** \\ ABO-BAKR S. BEHERY, M.D.*** and MOHAMED A.A. KHALEFA, M.D.*** \\ The Departments of Otorhinolaryngology*, Audiology** and Otolaryngology***, Faculty of Medicine, Tanta University
}

\begin{abstract}
Background: Steroids remain the treatment of choice for sudden hearing loss regardless the cause. With the adverse effects of systemic corticosteroids, Intratympanic injection of steroids appears to be an attractive method of management of Idiopathic Sudden Sensorineural Hearing Loss (ISSHL) in patients with contraindication for systemic steroids.
\end{abstract}

Patients and Methods: 40 patients, presented with moderate to severe and severe SSNHL were enrolled in the study. Patients were randomly allocated in one of two groups: (Group I) received intratympanic injection of dexamethasone $4 \mathrm{mg}$ for 5 times over 4 weeks and (Group II) received systemic steroid $1 \mathrm{mg} / \mathrm{kg}$ for one week and tapering the dose for two weeks. Pure Tone Audiogram (PTA) and Speech Discrimination (SD) were used for assessment pre and post-treatment in the two groups.

Results: Group I treated with intratympanic injection of dexamethasone showed hearing improvement in $45 \%$ of patients ( 9 patients) and no improvement in 55\% of patients (11 patients), while Group II treated with systemic corticosteroids showed hearing improvement in $60 \%$ of patients $(12$ patients) and no improvement in $40 \%$ of patients (8 patients). The degree of improvement showed no statistically difference between both groups.

Conclusions: The intratympanic injection of dexamethasone is an effective alternative to systemic steroids in treatment of ISSNHL as a primary therapy.

Key Words: Intratympanic dexamethasone injection - Sudden deafness - Steroid.

\section{Introduction}

SUDDEN Sensorineural Hearing Loss (SSNHL) is defined as a rapid onset, occurring over a 72hour period, of a subjective sensation of hearing impairment in one or both ears. Sudden Sensorineural Hearing Loss (SSNHL) meets certain audiometric criteria. (A) Sensorineural hearing loss indicates an abnormality of the cochlea, audi-

Correspondence to: Dr. Mostafa R.A. Lotfy, The Department of Otorhinolaryngology, Faculty of Medicine, Tanta University tory nerve, or higher aspects of central auditory perception or processing. (B) The most frequently used audiometric criterion is a decrease in hearing of _30 decibels (dB), affecting at least 3 consecutive frequencies. Idiopathic Sudden Sensorineural Hearing Loss (ISSNHL) is defined as SSNHL with no identifiable cause despite adequate investigation [1].

Corticosteroids may act in the inner ear to affect hearing not only by their anti-inflammatory effects but also by altering the inner ear's fluid and electrolyte balance, thus affecting endocochlear potential. Because of the blood-labyrinthine barrier, systemic steroids have a limited ability to reach the inner ear. Intratympanic corticosteroid therapy may potentially provide organ-specific treatment, with high doses applied over the round window membrane, thereby avoiding the adverse effects of systemic corticosteroid therapy [2].

Intratympanic steroids are used in one of three manners: As salvage therapy after failure of initial systemic steroids, in combination with systemic steroids as initial treatment, and alone as an initial treatment when systemic steroids or their side effects are not tolerated [3]

The aim of the work is to study the efficacy of intratympanic injection of dexamethasone for the treatment of idiopathic sudden sensorineural hearing loss, and compare between efficacy of Intratympanic injection of dexamethasone and administration of systemic corticosteroids.

\section{Patients and Methods}

This prospective case series study was carried out at ENT Department, Tanta University Hospitals from December 2015 to September 2017 on 40 patients with unilateral idiopathic moderate-severe 
and severe sudden sensorineural hearing loss within the first month of presentation after approval of the local ethical committee (approval code: 30585/ 11/15). Written informed consent was taken from parents of 40 patients 18 years old or older (to sign the written consent). Any sudden hearing loss with identified cause was excluded from the study. Patients were allocated to 2 groups. The treatment group (Group I) consisted of 20 patients with contraindication to systemic corticosteroids. They received intratympanic injection of dexamethasone $4 \mathrm{mg}$. The control group (Group II) received oral prednisolone. Patients in Group I received five intratypmanic injection of dexamethasone $4 \mathrm{mg}$ about $0.4-0.6 \mathrm{ml}$ each time. Cotton soaked with lidocaine spray applied to tympanic membrane for 10 minutes for surface anesthesia. 25-gauge spinal needle was introduced into the anterior superior portion of the tympanic membrane to allow air escape, and then the needle was reinserted in the posterior inferior portion of the tympanic membrane and injection of dexamethasone inside the tympanic cavity. The patient was asked to lay in supine position and his head was tilted to the other side and to remain in this position for 30 minutes after injection. The patient was asked not to swallow and to remain in this position for $30 \mathrm{~min}$ after injection.

Patients in Group II received systemic steroids in the form of oral prednisolone. They started with the $1 \mathrm{mg} / \mathrm{kg}$ for one week and tapering the dose for two weeks.

Hearing recovery was measured with Siegel's criteria [4]. According to this classification, type I (complete recovery) included patients whose final hearing level was better than $25 \mathrm{~dB}$ regardless of the size of the gain. Type II (partial recovery) included patients who showed more than $15 \mathrm{~dB}$ of gain and whose final hearing level was between 25 and $45 \mathrm{~dB}$. Type III (slight recovery) included patients who showed more than $15 \mathrm{~dB}$ of gain and whose final hearing level was poorer than $45 \mathrm{~dB}$; and type IV (no improvement) included patients who showed less than $15 \mathrm{~dB}$ of gain. Pure-Tone Audiometry (PTA) was performed on the initial day and the second week and after treatment and one month after-treatment.

\section{Results}

Regarding the demographic data as age and sex, in Group I, the age ranged from 26 years to 64 years with a mean age of $43.95 \pm 13.21$ years. In Group II, the age ranged from 19 years to 60 years with mean age of $39.45 \pm 12.47$ years. In Group I there were 13 males ( 65 percent) and 7 females (35 percent). In Group II, there were 11 males (55 percent) and 9 females (45 percent). There was no statistically significant difference between the two groups in these variables. There is no correlation between age or gender of patients and improvement in hearing $(p=0.275)$ and $(p=$ $0.475)$ in that order. Table (1).

There were forty patients in this study. Twenty one patients $(52.5 \%)$ showed hearing improvement, and divided according to Siegel's criteria to complete recovery was in five patients $(12.5 \%)$, partial recovery was in 10 patients $(25 \%)$, and slight improvement in 6 patients (15\%). No improvement was noticed in 19 patients $(47.5 \%)$. Table (2).

Comparing the two groups, Group I treated with ITI of dexamethasone showed hearing improvement in $45 \%$ of patients ( 9 patients) and no improvement in $55 \%$ of patients (11 patients), while Group II treated with systemic corticosteroids showed hearing improvement in $60 \%$ of patients (12 patients) and no improvement in $40 \%$ of patients (8 patients). The degree of improvement showed no statistically difference between two groups. $(p=0.720)$. Table (3).

There were no significant difference between the both groups before and after-treatment. The mean PTA in-Group I and Group II before-treatment was $74.38 \pm 16.99$ and $66.47 \pm 21.84$ respectively with no significant difference. And after-treatment, The average PTA in Group I and Group II was $56.33 \pm 21.46$ and $45.83 \pm 20.63$ respectively with no significant difference $(p=.123)$. Figs. $(1,2)$.

The speech discrimination in-Group I before and after-treatment with ITI of dexamethasone was $25.20 \pm 30.73$ and $44.50 \pm 36.01$ respectively with improvement about $19.30 \%$ which was a highly significant difference $(p=0.004 *)$. In-Group II before and after-treatment with ITI of dexamethasone was $37.40 \pm 33.27$ and $68.20 \pm 22.50$ respectively with improvement about $30.80 \%$ which was a highly significant difference $(p=0.001 *)$. Fig. (3).

Eight patients complained of vertigo immediately after injection, and all of these patients recovered within 10 minutes. Otalgia occurred in 2 patients after injection, which was relieved after 30 minutes. No cases of residual tympanic membrane perforation or otitis media was noted. No long term complications resulted from intratympanic steroid injection in any of the patients. 
Table (1): Relation between age and gender and degree of improvement.

\begin{tabular}{|c|c|c|c|c|c|c|c|c|c|c|}
\hline & \multicolumn{8}{|c|}{ Degree of improvement } & \multirow{3}{*}{$x^{2}$} & \multirow{3}{*}{$p$} \\
\hline & \multicolumn{2}{|c|}{$\begin{array}{l}\text { Complete } \\
\text { recovery }\end{array}$} & \multicolumn{2}{|c|}{$\begin{array}{l}\text { Partial } \\
\text { reco- } \\
\text { very }\end{array}$} & \multicolumn{2}{|c|}{$\begin{array}{l}\text { Slight } \\
\text { impro- } \\
\text { vement }\end{array}$} & \multicolumn{2}{|c|}{$\begin{array}{c}\text { No } \\
\text { impro- } \\
\text { vement }\end{array}$} & & \\
\hline & $\mathrm{N}$ & $\%$ & N. & $\%$ & N. & $\%$ & $\mathrm{~N}$. & $\%$ & & \\
\hline \multicolumn{11}{|c|}{ Age intervals: } \\
\hline$<20$ & 0 & 0 & 0 & 0 & 0 & 0 & 1 & 5.3 & 4.385 & 0.275 \\
\hline $21-40$ & 3 & 60 & 3 & 30 & 2 & 33.3 & 10 & 52.6 & & \\
\hline $41-60$ & 2 & 40 & 6 & 60 & 3 & 50 & 6 & 31.6 & & \\
\hline$>-60$ & 0 & 0 & 1 & 10 & 1 & 16.7 & 2 & 10.5 & & \\
\hline \multicolumn{11}{|l|}{ Gender: } \\
\hline Male & 2 & 40 & & & 3 & 50 & 11 & 57.9 & 2.785 & 0.475 \\
\hline Female & 3 & 60 & 2 & 20 & 3 & 50 & 8 & 42.1 & & \\
\hline
\end{tabular}

Table (2): Degree of improvement in the whole study patients.

\begin{tabular}{lll}
\hline \multirow{2}{*}{ Degree of improvement } & \multicolumn{2}{c}{ All study patients $(\mathrm{n}=40)$} \\
\cline { 2 - 3 } & $\mathrm{N}$. & $\%$ \\
\hline Complete recovery & 5 & 12.5 \\
Partial recovery & 10 & 25 \\
Slight improvement & 6 & 15 \\
No improvement & 19 & 47.5 \\
\hline
\end{tabular}

Table (3): Degree of Improvement according to treatment type.

\begin{tabular}{lccccccc}
\hline \multirow{2}{*}{$\begin{array}{l}\text { Degree of } \\
\text { improvement }\end{array}$} & \multicolumn{2}{c}{$\begin{array}{c}\text { Group I } \\
(\mathrm{n}=20)\end{array}$} & & \multicolumn{2}{c}{$\begin{array}{c}\text { Group II } \\
(\mathrm{n}=20)\end{array}$} & $\mathrm{X}^{2}$ & $p$ \\
\cline { 2 - 4 } & $\mathrm{N}$. & $\%$ & & $\mathrm{~N}$. & $\%$ & & \\
\hline Complete recovery & 2 & 10 & 3 & 15 & 1.340 & 0.720 \\
Partial recovery & 5 & 25 & 5 & 25 & & \\
Slight improvement & 2 & 10 & 4 & 20 & & \\
No improvement & 11 & 55 & 8 & 40 & & \\
\hline
\end{tabular}

\section{PTA}

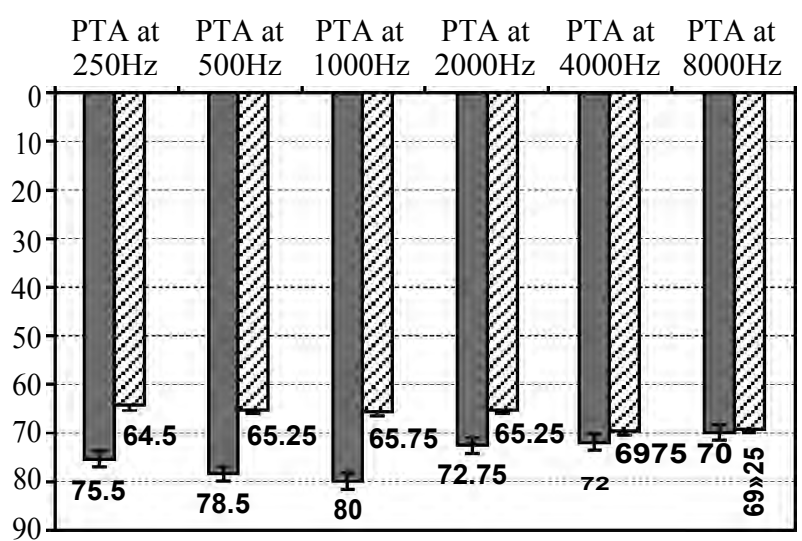

Group I $\quad Q$ Group II

Fig. (1): Description of Pure Tone Audiometry (PTA) before treatment.
PTA

PTA at PTA at PTA at PTA at PTA at PTA at $250 \mathrm{~Hz} \quad 500 \mathrm{~Hz} \quad 1000 \mathrm{~Hz} \quad 2000 \mathrm{~Hz} \quad 4000 \mathrm{~Hz} \quad 8000 \mathrm{~Hz}$

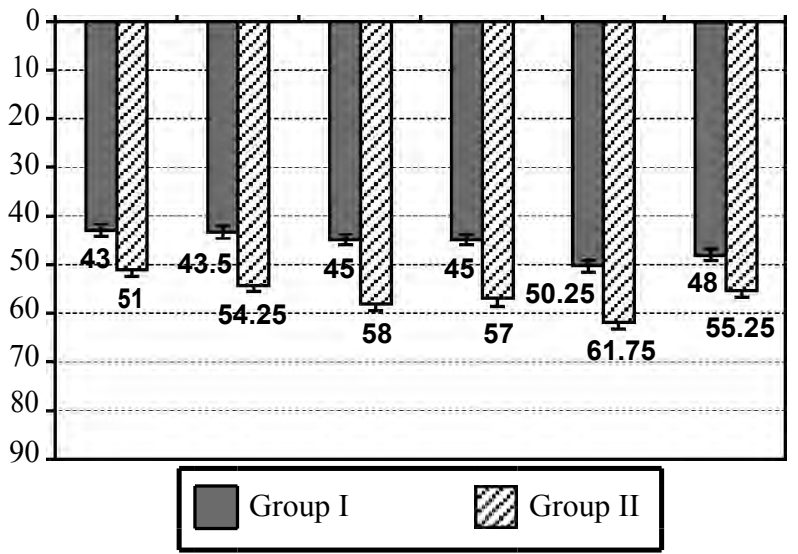

Fig. (2): Pure Tone Audiometry (PTA) after treatment in both groups.

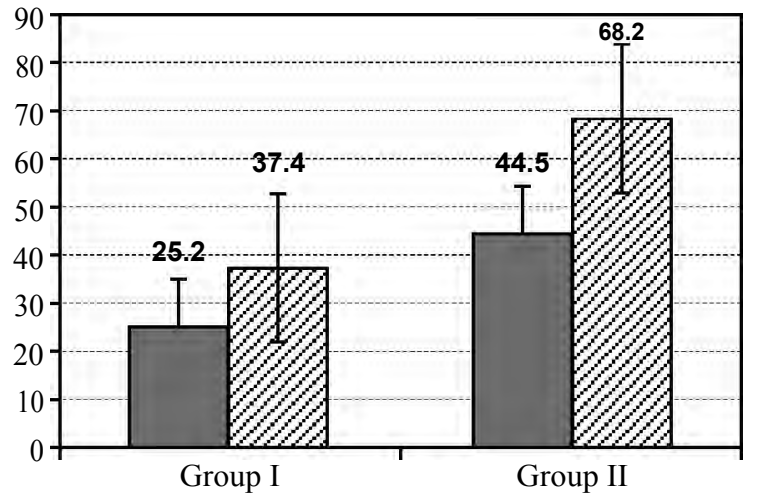

Sound discrmination

Before management

Fig. (3): Comparison of sound discrimination before and after treatment in both group.

\section{Discussion}

Sudden Sensorineural Hearing Loss (SSNHL) is an otologic emergency, and it is defined as $30 \mathrm{~dB}$ or greater shift in bone conduction thresholds in three consecutive frequencies occurring within 72 hours or less [5].

There are many advantages of ITI use. The main advantage is the possibility to treat all patients presenting with SSNHL avoiding systemic effects of steroids and thus treating those patients in which systemic steroids are contraindicated (i.e., immunocompromised patients, diabetics, tuberculosis, HIV). High dose regimen of steroids may expose patients (elder ones in particular) to various adverse effects: Glucose intolerance, avascular necrosis of the hip, insomnia, irritability, gastritis, and osteoporosis. Other advantages are: It is an officebased procedure, reduction in delay of start of 
treatment after diagnosis and to treat only the affected side and the possibility to combine ITSI with other systemic drugs without dangerous pharmacological interactions. Local administration of steroids via the middle ear cavity may act directly on the inner ear at a higher concentration [6,7]

The study included forty patients, 24 patients $(60 \%)$ were males and 16 patients (40) were females with a ratio $1.5: 1$ with no statistically significant difference in incidence of SSNHL or improvement of hearing after treatment ( $p=0.475)$. Our study agreed with Byl et al., [8], Cinamon et al., [9], that sex is not a prognostic factor in SSNHL. On the other hand, only Samim et al., [10] have shown that female patients had a better prognosis where the ratio between male:female 2.3:1 $(p<0.05)$.

In this study, the age of patients ranged from 19 to 64 years with mean age $41.5 \pm 22.5$. In the ITI group, the age ranged from 26 years to 64 years with a mean age of $43.95 \pm 13.21$ years. In systemic steroid group, the age ranged from 19 years to 60 years with mean age of $39.45 \pm 12.47$ years. There were no correlation between age of the patients and hearing improvement $(p=0.275)$. Incidence of SSNHL increased with age in the present study, with maximum number around 41 years, then the incidence decline after the age of 60 years. Byl et al., [8] also found increasing incidence with increasing age, with a peak incidence of 47 per 100,000 in patients 65 years and older. Teranishi et al., [11] reported a peak annual incidence of 58 per 100,000 in patients aged 60 to 64 in Japan, with a steep decline in incidence with increasing age above 65 years. Klemm et al., [12] reported bimodal peaks at 40 to 49 years and 60 to 69 years in Germany.

In this study, intratymoanic injection of dexamethasone results in improvement of PTA about $18.049 \mathrm{~dB}$ and improvement in speech discrimination about 18.25 \pm 24.19 . Both results was statistically significant. The percentage of subjects improved was $45 \%$. Parnes et al., [13] reported mean improvement of PTA about $62 \mathrm{~dB}$ and the percentage of subjects improved was $46 \%$. Banerjee and parnes [14] in another study reported mean improvement of PTA about $23 \mathrm{~dB}$ and the percentage of subjects improved was 50\%. Battisa et al., [15] reported mean improvement of PTA about $17 \mathrm{~dB}$ and the percentage of subjects improved was $12 \%$, although they used a larger concentration of dexamethasone $24 \mathrm{mg}$. All previously mentioned studies were prospective with no comparator group.

In our study, the comparator group that received oral corticosteroid treatment showed mean PTA improvement about $20.64 \mathrm{~dB}$. This is comparable with the $61 \%$ reported by Wilson et al., [16]. The improvement in sound discrimination in this group was $31.40 \pm 23.20$. The percentage of subjects improved $60 \%$. There is no significant difference in PTA improvement and sound discrimination between ITI group and oral corticosteroid group.

In 2011, Rauch et al., [17] conducted a multicenter prospective randomized controlled trial comparing the outcomes of primary treatment with oral prednisone and intratympanic methylprednisolone $(40 \mathrm{mg} / \mathrm{ml})$. They observed a mean Pure Tone Average (PTA) improvement of $30.7 \mathrm{~dB}$ in the oral prednisone group compared with $28.7-\mathrm{dB}$ improvement in the intratympanic group, and were able to reject null hypothesis of inferiority of intratympanic administration.

Battaglia et al., [18] observed superior hearing outcomes with the use of intratympanic $12 \mathrm{mg} / \mathrm{ml}$ dexamethasone alone compared with oral prednisone alone. Similarly, in a prospective, nonrandomized study, Kara et al., [19] also found superior hearing outcomes with intratympanic dexamethasone compared with oral methylprednisolone. Neither of these outcomes achieved statistical significance. No study has reported treatment with intratympanic steroids, alone or combination with systemic steroids, to be less effective than systemic steroids alone [3].

\section{Conclusion:}

From the results of the present study we concluded that The intratympanic injection of dexamethasone is effective in treatment of ISSNHL as a primary therapy. There is no statistically significant difference between treatment with intratympanic injection of dexamethasone and treatment with oral prednisone. Intratympanic dexamethasone injection is a suitable alternative if there are medical contraindications to systemic steroids.

\section{Limitations:}

The superiority of ITI in comparison to systemic steroids still needs to be reproduced in level I studies, before they can replace them as the mainstay treatment modality of this condition, and a universal treatment protocol for ISSNHL has to be further evaluated. A larger study group, a later time of presentation, and a longer follow-up periods are recommended for further studies.

\section{Acknowledgments:}

NAD. 


\section{Funding:}

The research was done in Tanta University Hospital with no other funding resources.

\section{Conflicts of interest:}

No conflicts of interest declared.

\section{Authors' contributions:}

All authors had equal role in design, work, statistical analysis and manuscript writing.

\section{References}

1- METRAILER A.M. and BABU S.C.: Management of sudden sensorineural hearing loss. Curr. Opin. Otolaryngol. Head Neck Surg.; 24 (5): 403-6, 2016.

2- CHANDRASEKHAR S.S.: Intratympanic dexamethasone for sudden sensorineural hearing loss: Clinical and laboratory evaluation. Otolo. Neurotol.; 22 (1): 18-23, 2001.

3- HOBSON C.E., ALEXANDER T.H. and HARRIS J.P.: Primary treatment of idiopathic sudden sensorineural hearing loss with intratympanic dexamethasone. Curr. Opin. Otolaryngol. Head Neck Surg.; 24 (5): 407-12, 2016.

4- SIEGEL L.: The treatment of idiopathic sudden sensorineural hearing loss. Otolaryngol. Clin. North Am.; 8 (2): 467, 1975.

5- LEE H.Y., KIM D.K., PARK Y.H., CHA W.W., KIM G.J. and LEE S.H.: Prognostic factors for profound sudden idiopathic sensorineural hearing loss: A multicenter retrospective study. Eur. Arch. Otorhinolaryngol.; 274 (1): 143-9, 2017.

6- ZHAO D., TONG B., WANG Q., HELLSTROM S. and DUAN M.: A comparison of effects of systemic and intratympanic steroid therapies for sudden sensorineural hearing loss: A meta-analysis. J. Otol.; 11 (1): 18-23, 2016.

7- DISPENZA F., AMODIO E., De STEFANO A., GALLINA S., MARCHESE D., MATHUR N., et al.: Treatment of sudden sensorineural hearing loss with transtympanic injection of steroids as single therapy: A randomized clinical study. Eur. Arch. Otorhinolaryngol.; (9): 12738, 2011.

8- BYL F.M.: Sudden hearing loss: Eight years' experience and suggested prognostic table. The Laryngoscope; 94 (5): 647-61, 1984.
9- CINAMON U., BENDET E. and KRONENBERG J.: Steroids, carbogen or placebo for sudden hearing loss: A prospective double-blind study. Eur. Arch. Otorhinolaryngol.; 258 (9): 477-80, 2001.

10- SAMIM E., K1L1C R., OZDEK A., GOCMEN H., ERY1LMAZ A. and UNLU I.: Combined treatment of sudden sensorineural hearing loss with steroid, dextran and piracetam: Experience with 68 cases. Eur. Arch. Otorhinolaryngol.; 261 (4): 187-90, 2004.

11- TERANISHI M., KATAYAMA N., UCHIDA Y., TOMINAGA M. and NAKASHIMA T.: Thirty-year trends in sudden deafness from four nationwide epidemiological surveys in Japan. Acta Oto-laryngologica; 127 (12): 125965, 2007.

12-KLEMM E., DEUTSCHER A. and MÖSGES R.: A present investigation of the epidemiology in idiopathic sudden sensorineural hearing loss. Laryngo-rhino-otologie; 88 (8): 524-7, 2009.

13- PARNES L.S., SUN A.H. and FREEMAN D.J.: Corticosteroid pharmacokinetics in the inner ear fluids: An animal study followed by clinical application. The Laryngoscope; 109 (S91): 1-17, 1999.

14- BANERJEE A. and PARNES L.S.: Intratympanic corticosteroids for sudden idiopathic sensorineural hearing loss. Otol. Neurotol.; 26 (5): 878-81, 2005.

15- BATTISTA R.A.: Intratympanic dexamethasone for profound idiopathic sudden sensorineural hearing loss. Otolaryngol. Head Neck Surg.; 132 (6): 902-5, 2005.

16- WILSON W.R., BYL F.M. and LAIRD N.: The efficacy of steroids in the treatment of idiopathic sudden hearing loss: A double-blind clinical study. Archives of Otolaryngology;106 (12): 772-6, 1980.

17- RAUCH S.D., HALPIN C.F., ANTONELLI P.J. BABU S.; CAREY J.P., GANTZ B.J., et al.: Oral vs intratympanic corticosteroid therapy for idiopathic sudden sensorineural hearing loss: A randomized trial. Jama; 305 (20): 20719, 2011.

18- BATTAGLIA A., BURCHETTE R. and CUEVA R.: Combination therapy (intratympanic dexamethasone + high-dose prednisone taper) for the treatment of idiopathic sudden sensorineural hearing loss. Otol. Neurotol.; 29 (4): 453-60, 2008.

19- KARA E., ÇETIK F., TARKAN Ö. and SÜRMELIO GLU Ö.: Modified intratympanic treatment for idiopathic sudden sensorineural hearing loss. Eur. Arch. Otorhinolaryngol.; 267 (5): 701-7, 2010. 


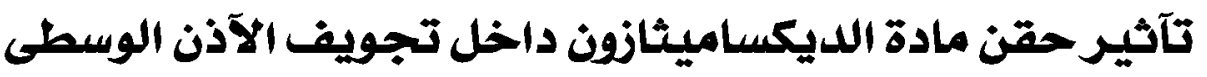

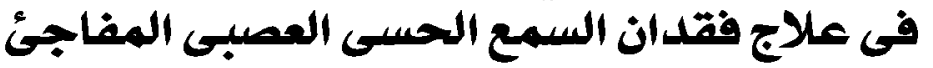

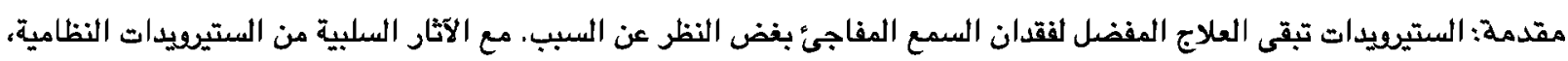

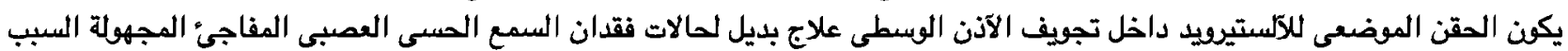

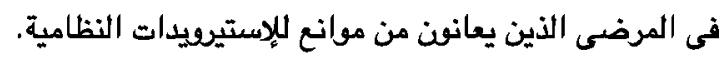

المرضى وطريقة البحث: تشمل هذه الدراسة آربعين مريضا يعانف من فقدان سمعى حسى عصبى مفاجئ مجهول السبب. ويقسم

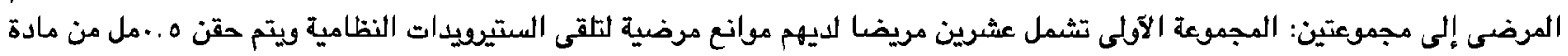

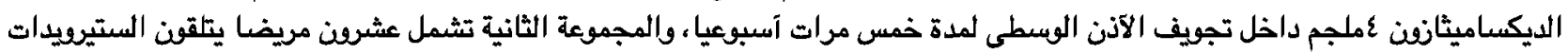
النظامية بجرعة املجم/كج لمدة آسبوع ويتم تقليل الجرعة على مدار آسبوعين. يتم عمل ربسم سمع وإختبار تمييز الكلام قبل وبعد العلاج.

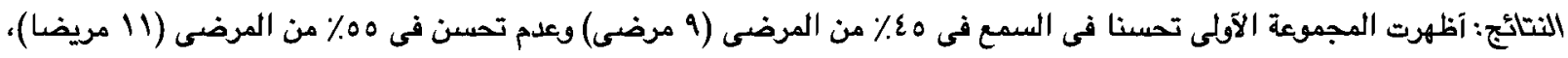

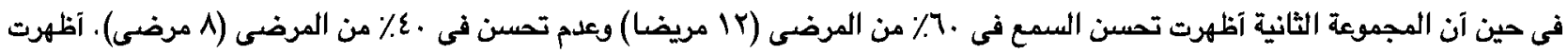
درجة التحسن عدم وجود فرق إحصائى بين المجموعتين.

الإسستّاج: حقن الديكساميثًانف داخل تجويف الآنن الويسطى فى حالات فقدان السمع الحسى العصبى المفاجئ هو بديل فعال للإستيرويدات النظامية في حالة وجود مانع لتناولها. 